- Regulation of laser use is similar to that employed for X-radiation.

- The prime risk is associated with the unprotected eye. Damage can be instantaneous and permanent. All lasers are classified according to this risk.

- Regulation in the UK is through the Healthcare Commission in the implementation of internationally-accepted guidelines as to all aspects of laser safety in the dental surgery.

- It is the responsibility of all clinicians undertaking laser dentistry to observe safe practice

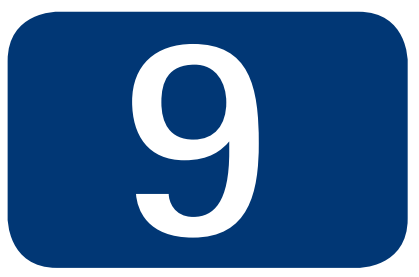
and, where required, register such use with regulatory authorities.

\title{
Laser regulation and safety in general dental practice
}

\section{S. Parker ${ }^{1}$}

\begin{abstract}
Laser devices, instruments and machines vary in their potential for light energy emission from low-powered hand-held or integrated devices, to high-powered units capable of cutting and ablating tissue and materials. The safe use of lasers in dentistry extends to all personnel who might be exposed, either deliberately or by accident, and demands of the lead clinician an approach to their use in order that risk of accidental exposure to laser light is minimised. The scope for regulations extends in similar ways to those imposed on the use of ionising radiation in the dental practice. Laser safety measures in the dental surgery are often drawn from the safe approach to the use of lasers in general and other specialties in medicine and surgery. This article serves to examine the risks involved in laser use in dentistry, the regulations governing safe use and the responsibilities of personnel involved in providing treatment to patients.
\end{abstract}

\begin{tabular}{|l|}
\hline LASERS IN DENTISTRY \\
\hline $\begin{array}{l}\text { 1. Introduction, history of lasers and } \\
\text { laser light production }\end{array}$ \\
\hline 2. Laser-tissue interaction \\
\hline 3. Low-level laser use in dentistry \\
\hline $\begin{array}{l}\text { 4. Lasers and soft tissue: 'loose' soft } \\
\text { tissue surgery }\end{array}$ \\
\hline $\begin{array}{l}\text { 5. Lasers and soft tissue: } \\
\text { 'fixed' soft tissue surgery }\end{array}$ \\
\hline $\begin{array}{l}\text { 6. Lasers and soft tissue: } \\
\text { periodontal therapy }\end{array}$ \\
\hline $\begin{array}{l}\text { 7. Surgical laser use in } \\
\text { implantology and endodontics }\end{array}$ \\
\hline $\begin{array}{l}\text { 8. Surgical lasers and hard dental } \\
\text { tissue }\end{array}$ \\
\hline $\begin{array}{l}\text { 9. Laser regulation and safety in } \\
\text { general dental practice }\end{array}$ \\
\hline
\end{tabular}

${ }^{1}$ General Dental Practitioner, 30 East Parade, Harrogate, North Yorkshire, HG1 5LT

Correspondence to: Dr Steven Parker Email: thewholetooth@easynet.co.uk

\section{Refereed Paper}

British Dental Journal 2007;

202: 523-532

DOI: $10.1038 /$ bdj.2007.370

\section{REGULATIONS AS TO USE OF LASERS IN DENTISTRY}

As described earlier, the expansive development of laser use in medicine and surgery occurred during the 1970s and early 1980s. In the UK, sufficient concern was raised as to the suitability of training and regulation of practitioners using lasers, which resulted in a timely amendment to the Nursing Homes Act in 1985. Although laser use was considered peripheral to the core of the Act, compulsory registration of medical (and, after 1990, dental) practitioners with local health authorities was required, in addition to a general compliance under the Health and Safety Act. With respect to dental practice, the new 'laser dentists' using surgical lasers received perfunctory inspection from health authority personnel. Although the auspices of the Nursing Homes Act were expansive, dental practice inspection was often limited to an assessment by a laser protection advisor (usually a medical physicist), as to the suitability of premises, controlled area, local rules and training record of dentists using these lasers.

In 2000, the Nursing Homes Act was replaced by the Care Standards Act and the setting up of the Healthcare Commission in $2004^{1}$ has resulted in a much more specific attitude to the regulation of all personnel who use both lasers and intense light sources. Notwithstanding the extent of the scope of interest shown by this authority towards the provision of primary healthcare in general, and the implications for general dental practitioners who use lasers, specifically the duty of the practitioner, in using surgical lasers can be listed as follows:

- Application for registration as a user of a surgical laser with the Healthcare Commission

- Demonstration of physical barriers to safeguard safety - controlled area, limited access

- Demonstration of training received by all involved in laser use, local rules, and a record of laser use

- Demonstration of suitability of laser for clinical use, machine maintenance, and laser safety eye protection

- Recording and audit of unwanted effects associated with laser use.

In contrast to other countries, there is as yet no statutory requirement per se for formal 
Fig. 1 Risk analysis relative to tissue and laser class

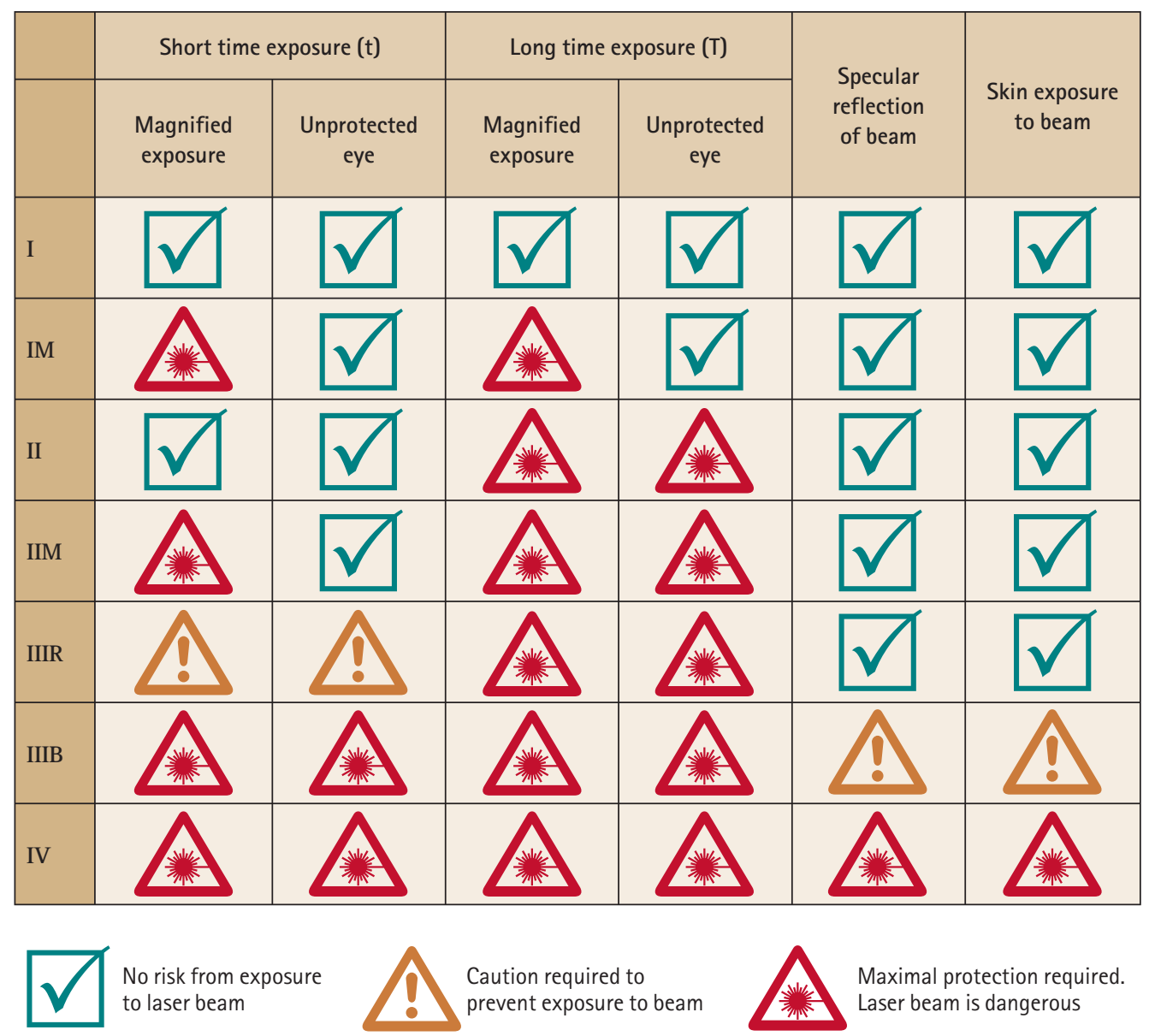

Fig. 2 Illustration of the transmissive (inverse of absorption) nature of visible and near-infrared wavelengths through the cornea, lens and associated structures. Above $1,400 \mathrm{~nm}$, there is increased absorption by the water content of these structures

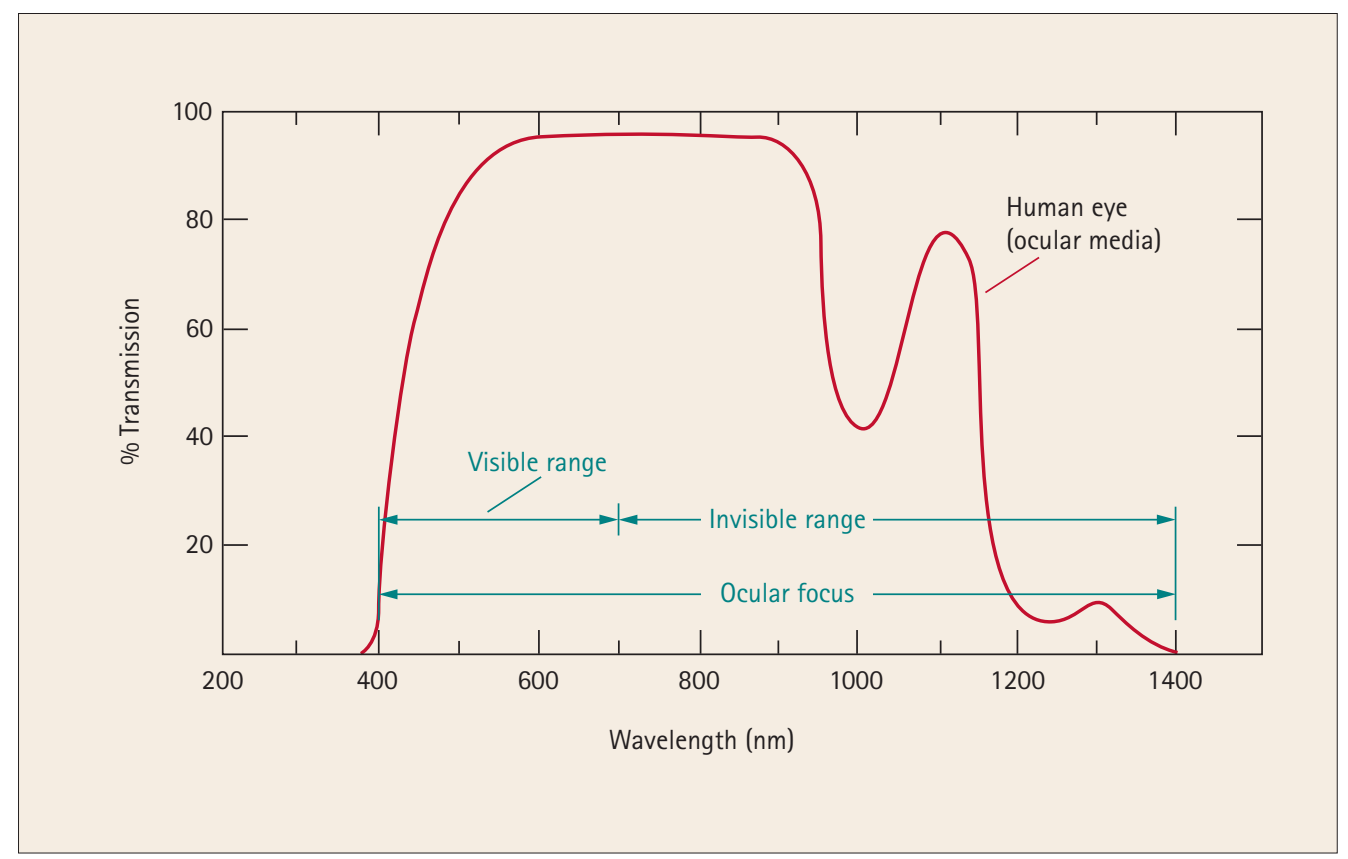

or on-going training or education in the use of lasers in dentistry in the UK. The Healthcare Commission would view attendance at postgraduate courses, such as those offered by the European Society for Oral Laser Applications (ESOLA) and the Academy of Laser Dentistry (ALD), as being indicative of ongoing training and proficiency examinations given by such organisations are accepted by the Healthcare Commission as evidence of the suitability of the practitioner to use surgical lasers on patients.

The specifics of safety with regard to the use of lasers extend primarily to eye protection, although target oral tissue exposure is important; the parallel requirements of regulations with regard to ionising radiation equipment can be readily appreciated. 


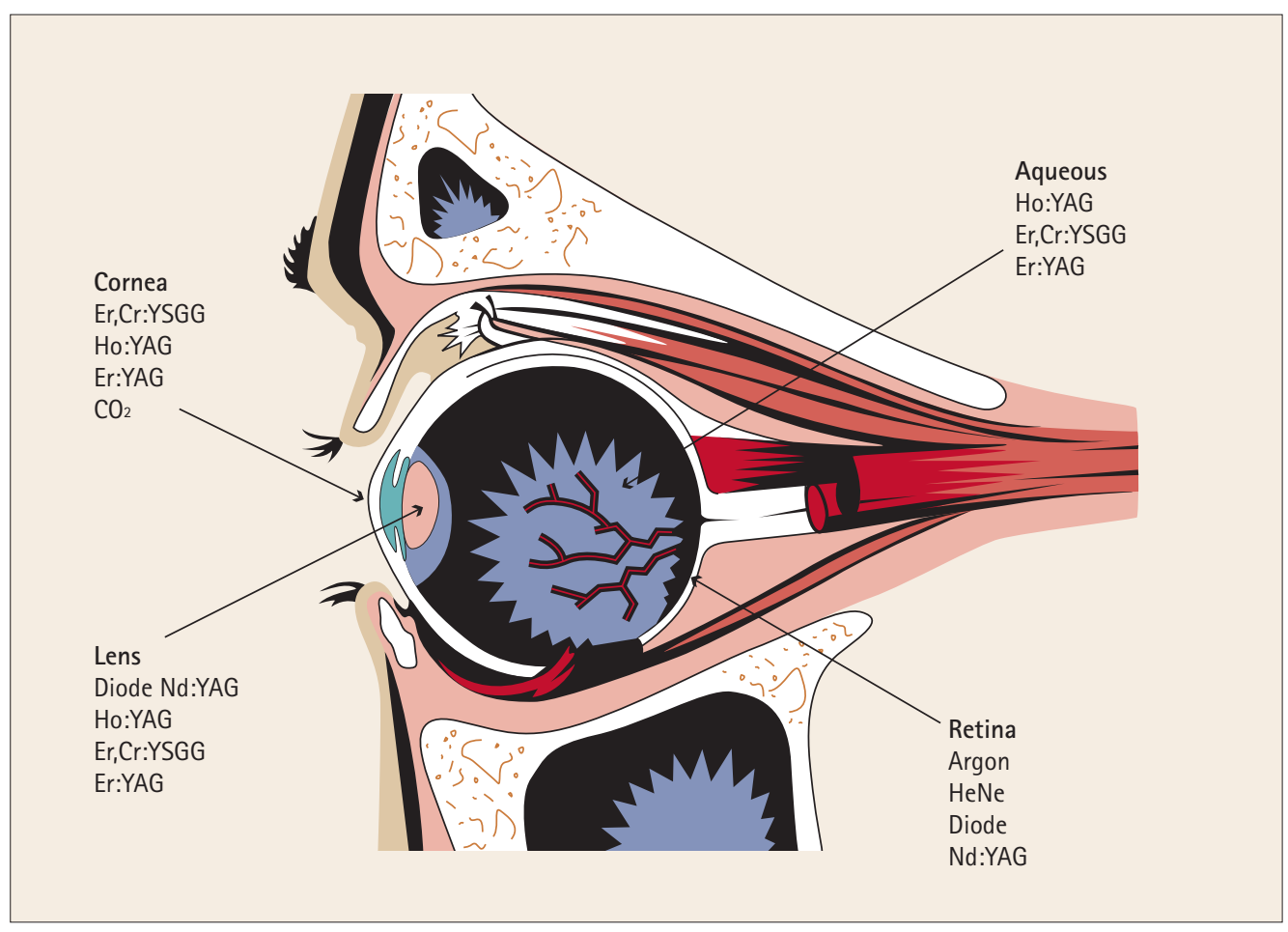

Fig. 3 Wavelength/site risk analysis of the eye. Non-pigmented structures towards the front of the eye will be most at risk from longer wavelengths, whereas retinal structures are at risk from short infrared and visible wavelengths

\section{LEGAL ASPECTS OF LASER USE IN DENTAL PRACTICE}

The first guidelines were issued in the 1960s, by defence research organisations in the US and the UK, and then by the American Conference of Governmental Industrial Hygienists. ${ }^{2}$ However, with regard to any laser used in dental practice, as in any healthcare establishment, general safety legislation will apply, such as the Health and Safety at Work, etc Act 1974, the Management of Health and Safety at Work Regulations 1999, the Provision and Use of Work Equipment Regulations 1998 and the Personal Protective Equipment at Work Regulations 1992. ${ }^{3}$ Compliance with the current British Standard on laser safety, BS EN 60825-1:1994, is required under European directives for many laser products. In addition, as with any product sold for medical use, any laser sold in the European Community must carry a 'CE' mark (the CE Marking Directive 93/68/EEC was adopted in 1993 - 'Conformité Européene', which literally means 'European conformity'). The CE mark proves to buyers that the product (production prototype) fulfils all the essential safety and environmental requirements as defined in the European directives.

The safety of lasers is based on the proper design of laser equipment and on the adoption of appropriate precautions during use. What discrepancy that might have occurred between the policies adopted by the USA and North America and other major regions, has been somewhat unified through the definition and adoption of the recommendations of the International Electro-technical Commission (IEC). This has resulted in a broad set of regulations that safeguard the product licence of laser machines and define

\begin{tabular}{|c|c|c|c|c|c|c|c|}
\hline Pre-2002 & I & & II & & IIIA & IIIB & IV \\
\hline Post-2002 & I & IM & II & IIM & IIIR & IIIB & IV \\
\hline
\end{tabular}

protection measures for personnel who are associated with their use. Detailed requirements are given in a number of recognised safety standards, the principal international standard for laser safety being IEC 60825-1. ${ }^{4}$ This standard applies throughout much of the world, and is adopted in Europe as EN 608251, where it is used in support of various European directives. ${ }^{5}$ The USA has always had its own regulation on lasers (known as 21 CFR 1040.10); this is a USA government regulation (rather than a standard) and is written into US law. However, the issue of FDA Laser Notice 50 in 2001, sought to inform laser product manufacturers that the US FDA will now accept IEC classification and labelling.

The IEC recommendations are expanded through two instruments:

1. CE ('Conformité Européene') Marking Directive (93/68/EEC) 1993 Laser Product Licence, which defines suitability for use, clinical parameters, safety features of lasers, environment safety, patient safety, LSO, laser protection advisor, administrative code, record keeping and laser maintenance

2. IEC (EN) 60825-1:2001 'Safety of laser products part 1: equipment classification, requirements and user's guide', which defines laser classes and measurement conditions, labelling, engineering controls etc, maximum permissible exposures (MPE) and accessible emission limits (AEL). 
Fig. 4 The potential risks posed by surgical lasers within the clinical workplace. Source: Health Protection Agency UK
Fig. 5 (left) Laser warning sign, wavelength designated

Fig. 6 (right) Emergency 'STOP' button

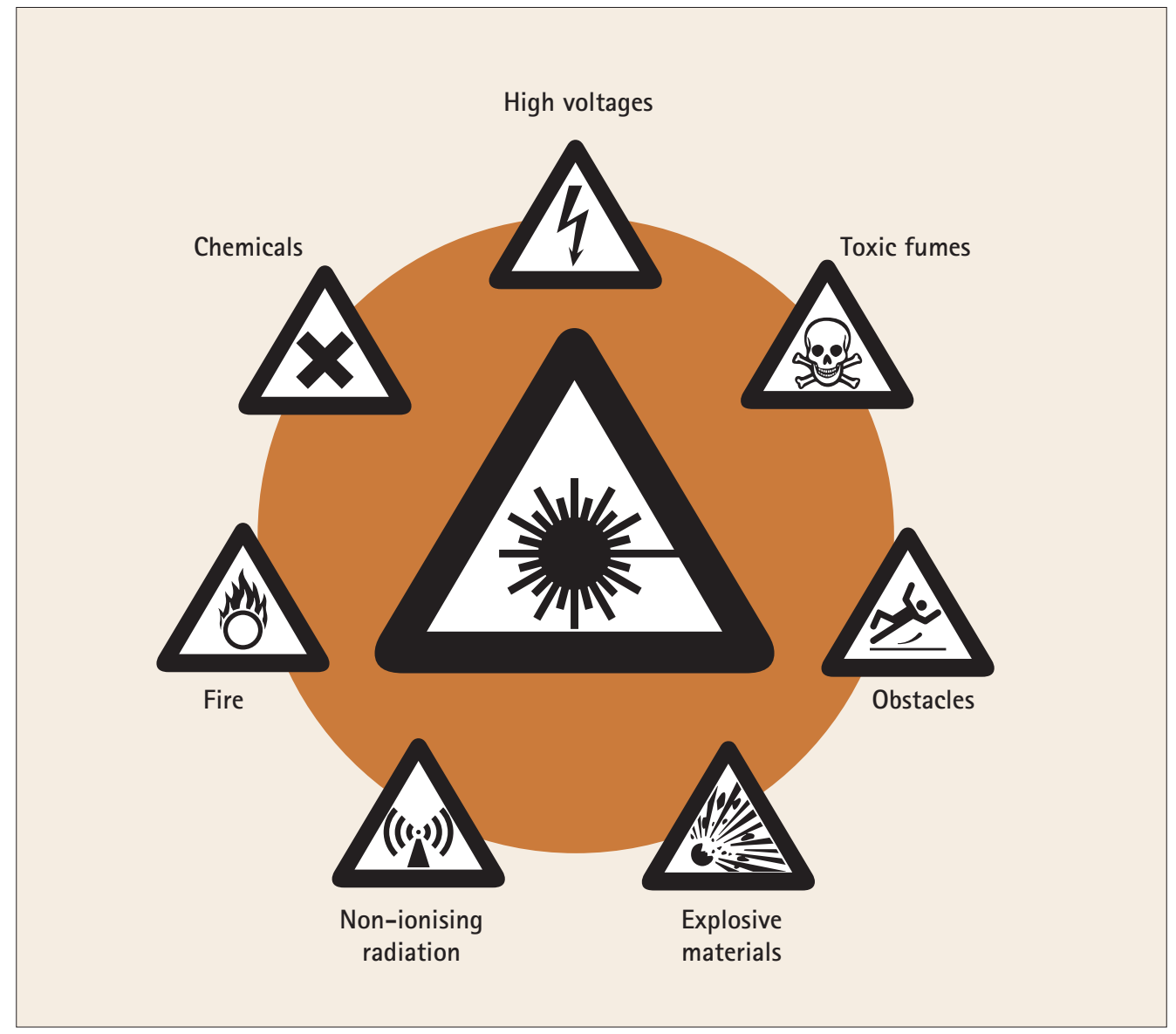

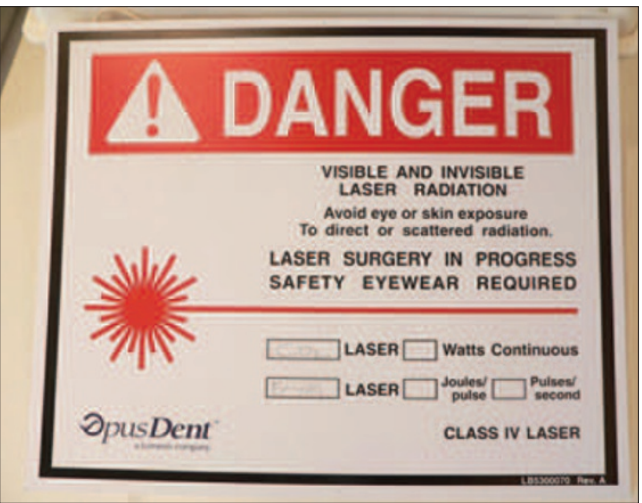

Within the UK, the regulation of practices wishing to use surgical and other powerful lasers is undertaken by the Healthcare Commission, which draws upon legislation outlined above in its determination of safe and proper use. The Healthcare Commission has taken over the work of The National Care Standards Commission in ensuring compliance with the Care Standards Act 2000, which denotes national minimum standards for laser use. Dental practices using powerful lasers (Class 4 - see below) must register with the Healthcare Commission. ${ }^{6}$

\section{LASER CLASSIFICATION}

Originally, the classification of lasers used in healthcare was through an ascending Class I-Class IV to denote increased risk associated with use, and this classification is still in operation in the USA (I, IIA, II, IIIA, IIIB

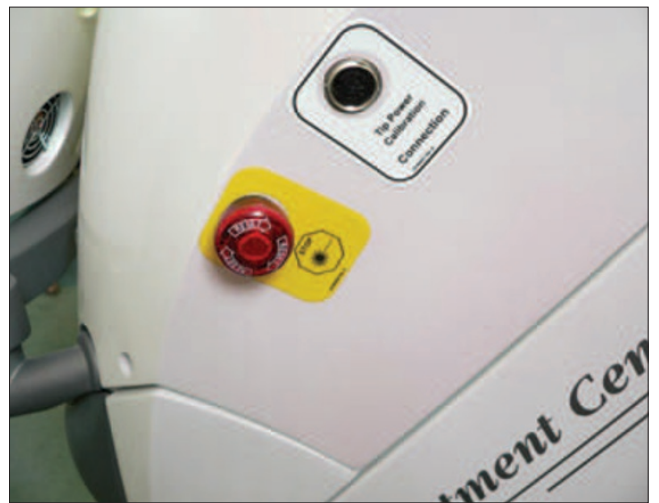

and IV). In the light of IEC recommendations, such classification has been revised to reflect exposure during use with magnification instruments, such as surgical microscopes. An overview of the classes of lasers, which represents their essential power, is given in Table 1.

The classification recognises risks associated with laser use and hazards pertaining to exposure of the eye and other tissues to the laser beam. ${ }^{7-9}$ A 'worst case' scenario is adopted, which includes minimal distance from the laser, prolonged exposure to laser light and an assumption that non-protective spectacles are worn. Lasers have to be properly labelled to indicate their class and to warn users of their potential hazard. They must also incorporate certain safety features, dependent on their class, which are specified in the safety standard. 
In 2002, a revision in accordance with European Standard EN 60825-1 was undertaken, with respect to maximum permissible exposure levels (MPEs), which rendered the adoption of the new classification. Individual MPE values vary according to the varying sensitivity of possible target tissues, eg the eye and skin and are expressed in Joules or Watts per area $\left(\mathrm{J} \mathrm{cm}^{-2}, \mathrm{~W} \mathrm{~cm} \mathrm{~cm}^{-2}\right) .{ }^{10}$ Generally, the longer the wavelength, the higher the MPE value; the longer the exposure time, the lower the MPE value.

\section{Classes of laser}

Class I: examples are found in CD players and laser caries detectors. Viewing with the naked eye poses no implicit risk, but caution should be observed if wearing spectacles or using optical devices (Class IM - 'magnifying'). The maximum power output of these lasers is $40 \mu \mathrm{W}$ (blue light) and $400 \mu \mathrm{W}$ for red light emissions.

Class II: examples are laser pointers. There exist specific risks to viewing light emissions, both to the naked eye and when using magnification. ${ }^{11,12}$ The maximum output is $1 \mathrm{~mW}$.

Class III: the 'old' Class IIIA is replaced by Classes IM and IIM. Class IIIB represents maximal power output of $0.5 \mathrm{~W}$. Examples include 'soft' medical lasers (LLLT), laser light show equipment and laser measuring devices. Environmental controls, protective eyewear, appointment of assigned safety personnel (laser safety officer, laser protection advisor) and training in laser safety are required by personnel using these lasers. ${ }^{13}$

A new classification is the Class IIIR, which may also include some low level medical devices and targeting lasers, but generally lasers of lower power outputs than IIIA. For emission in the visual range of wavelengths (400-700 $\mathrm{nm}$ ), the maximum power output is $5 \mathrm{~mW}$ and with invisible wavelengths, $2 \mathrm{~mW}$. The same safety measures are required as with Class IIIB lasers. ${ }^{14}$

Class IV: This Class includes all high-powered, surgical and other cutting lasers. There is no upper limit of power output. All surgical lasers used in dentistry and oral and maxillofacial surgery are included. The protective measures applicable to Class III lasers are further endorsed with the additional risk of fire hazards, due to flash-point temperatures being reached in chemicals used adjunctively to surgical procedures. This group of lasers represents the greatest risk of damage, both to unprotected persons and target tissue, either through direct or reflected and scattered beams. ${ }^{15}$

The new grouping classification can be used to define the broader risks associated with inadvertent use. The greater aspects of laser safety for unprotected personnel can be grouped as instantaneous eye exposure, longer (magnified) eye exposure, direct or specular reflected beam exposure and skin (non-occular) exposure. The relative risks

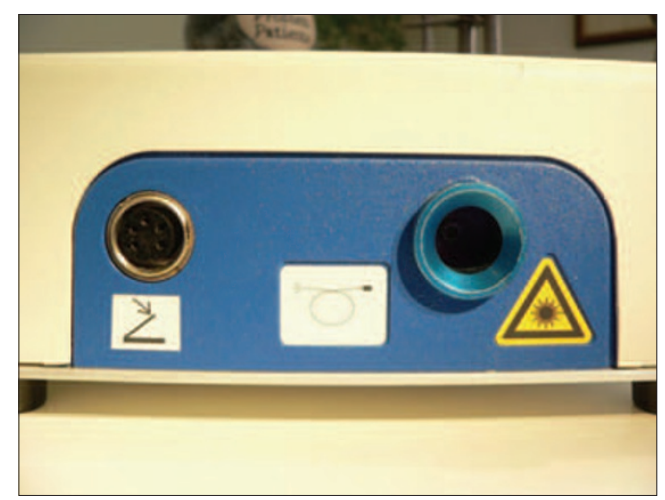

Fig. 7 Ports for foot-pedal and fibre

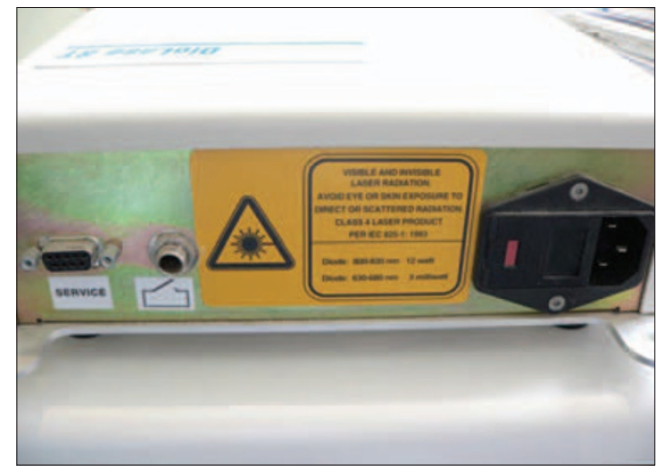

Fig. 8 Backplate, diode $810 \mathrm{~nm}$ laser, showing service port, remote interlock port and mains electricity socket (fused)

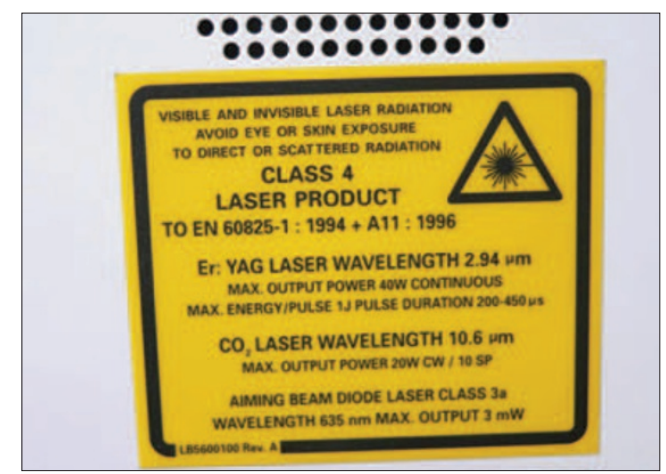

Fig. 9 Back-plate, Er:YAG/ $/ \mathrm{CO}_{2}$ laser

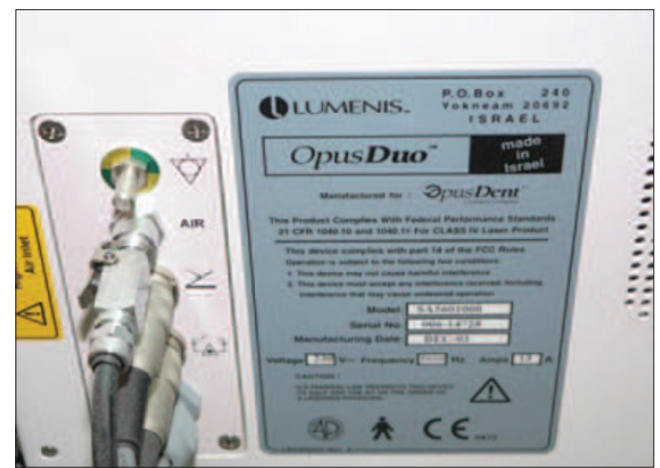

Fig. 10 Backplate, Er:YAG/ $\mathrm{CO}_{2}$ laser showing mains supply ports

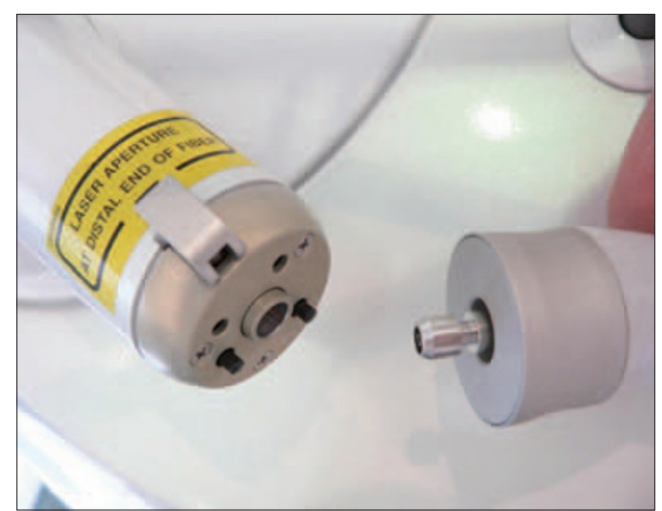

Fig. 11 Designated delivery system with unique interlock/wavelength 
Fig. 12 (left) Password-protected screen

Fig. 13 (right) Key-activated laser, showing 'error code' due to fibre/ foot pedal not connected
Fig. 14 (left) Protection for foot pedal

Fig. 15 (right) Laser protection glasses with side-shields
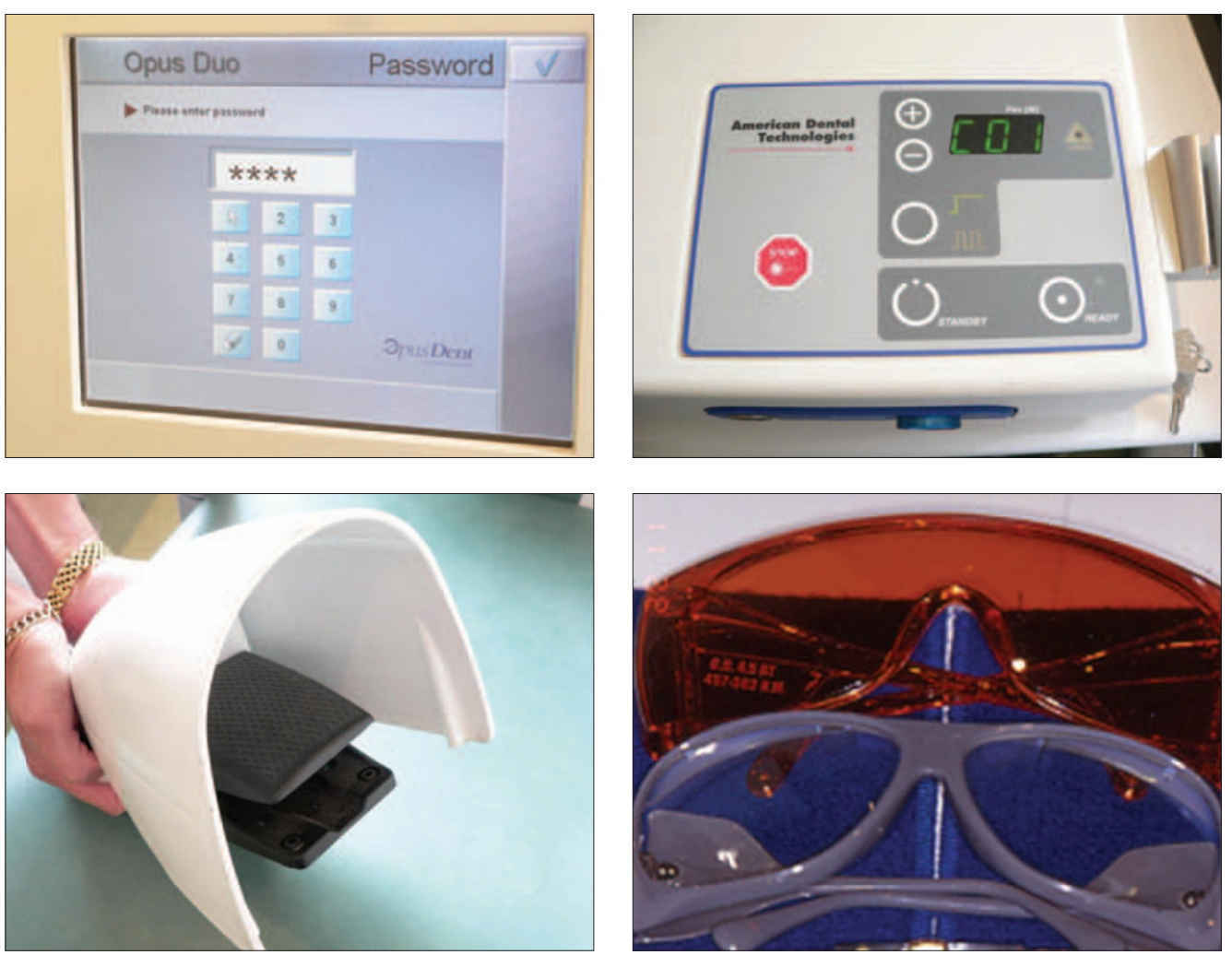

posed by the revised classification are summarised in Figure 1.

The remainder of this article will address safety issues associated with Class IV (mainly) and Class III lasers.

\section{RISKS ASSOCIATED WITH LASER USE \\ Laser beam risks}

These risks are those that are posed by exposure of non-target tissues to laser beams. Because of the intensity of the output beam and the ability of lasers to produce very high concentrations of optical power at considerable distances, these lasers can cause serious injuries to the eyes and can also burn the skin.

Optical risks: the majority of laser-induced ocular injuries are considered due to operator error. ${ }^{16}$ In general and with specific reference to lasers used in dentistry, there exist two groups of wavelengths that can adversely affect the eye. ${ }^{17,18}$ Wavelengths from 400$1,400 \mathrm{~nm}$ (visible and near-infrared) can pass through the transparent structures at the front of the eye and impact on the retina (Fig. 2). Longer wavelengths (2,780-10,600 $\mathrm{nm}$, mid- to far-infrared), will interact with the cornea.

In terms of the scope for repair, retinal injuries are more serious. ${ }^{19-22}$ Due to the focussing ability of the lens, a $1 \mathrm{~mW}(0.001$ $\mathrm{W})$ laser beam, passing to the back of the eye, results in a retinal irradiance more than 300 $\mathrm{W} \mathrm{cm}^{-2}$, well above the ablation threshold. Visible wavelengths may selectively destroy red or green cones, resulting in some colour blindness, although the majority of retinal laser burns affect complete areas of tissue due to the predominance of invisible wavelengths in dental lasers. Retinal injury may initially pass unnoticed, due to the lack of pain receptors. ${ }^{16}$

Longer wavelengths will interact with structures at the front of the eye, causing ablation, scarring and distortion of vision ${ }^{23}$ (Fig. 3).

Skin risks: Whilst UV lasers $(<400 \mathrm{~nm})$ are not commercially used in dentistry, there is a combined risk of ablative damage to skin structure and possible ionising effects that may be pre-cancerous. All other laser wavelengths can cause "skin burns' 24,25 due to ablative interaction with target chromophores.

\section{Non-beam risks}

These risks are associated with possible physical damage arising from moveable components of a laser, electrical shock and mains supplies (pressurised air, water). Fire risks, through the ignition of tubing, some anaesthetic gases or chemicals (eg alcoholic disinfectants), should be identified and avoided. ${ }^{26-30}$ In addition, the products of tissue ablation (plume) represent a considerable hazard that can affect the clinician, auxiliary personnel and the patient. Suitable fine mesh face masks specific to surgical laser use, gloves and high-speed suction aspiration must be used to control the spread of all laser tissue ablation products (see Fig. 4).

\section{Laser plume}

Products of laser tissue ablation are collectively termed a 'laser plume'. Whenever noncalcified tissue is ablated, such as in caries removal and all soft tissue surgery, a complex chemical mixture is emitted. This may include water vapour, hydrocarbon gases, carbon 
monoxide and dioxide and particulate organic material (including bacteria and viral bodies). The effect of plume inhalation can be serious and cause nausea, breathing difficulties and distant inoculation of bacteria. ${ }^{31-34}$ The plume arising from mid-infrared wavelength ablation of dental hard tissue is comparatively less potentially dangerous and can be considered similar to the debris that is produced with an air turbine.

\section{LASER SAFETY MEASURES}

Within the governing regulations, there exists a need for all specific and stochastic risks to be explored and measures taken to minimise their occurrence. Safety measures applicable to laser use in dental practice can be listed as follows:

- Environment

- Laser protection advisor/laser safety officer

- Access

- Laser safety features

- Eye protection

- Test firing

- Local rules

- Training.

\section{Environment}

The concept of laser beam collimation is only true for transmission in a vacuum, or at its immediate exit from the laser cavity. In air, and certainly through a delivery system with or without focussing devices, some divergence will occur. Accepting the power output, amount of divergence and beam diameter and configuration, a nominal ocular hazard distance (NOHD) can be assessed. ${ }^{35}$ This is a distance from the laser emission, beyond which the tissue (eye) risk is below the MPE. This is a complex calculation that can be done by a medical physicist, but for a Class IV dental laser, this distance is approximately three metres.

Consequently, as with ionising radiation, the concept of a controlled area can be adopted, within which only those personnel directly involved in laser delivery can enter and with specified protection. ${ }^{36-39}$ The controlled area must be delineated with warning signs (Fig. 5) that specify the risk, windows, doors and all surfaces should be non-reflective and access throughways either supervised or operated by remote inter-locks during laser emission. A secure locked designated place for the laser key, if applicable, should be assigned, together with a designated place for all laser accessories. In addition, a suitable fire extinguisher should be sited for easy access.

\section{Safety officers}

Dental practices offering Class IIIB and IV laser treatment, must appoint a laser protection advisor (LPA) and a laser safety officer (LSO). The LPA is usually a medical physicist who will advise on the protective devices required, MPE and NOHD for any given laser wavelength being used. The LSO is appointed to ensure that all safety aspects of laser use are identified and enforced. Ideally, this could be a suitably trained and qualified dental surgery assistant. Duties of the LSO include the following:

- Confirm classification of the laser

- Read manufacturers' instructions concerning installation, use and maintenance of the laser equipment

- Make sure that laser equipment is properly assembled for use

- Train workers in safe use of lasers

- Oversee controlled area and limit access

- Oversee maintenance protocols for laser equipment

- Post appropriate warning signs

- Recommend appropriate personal protective equipment such as eye wear and protective clothing

- Maintain a log of all laser procedures carried out, relative to each patient, the procedure and laser operating parameters

- Maintain an adverse effects reporting system

- Assume overall control for laser use and interrupt treatment if any safety measure is infringed.

\section{Access}

Relative to, for example, a hospital operating theatre, most dental surgeries exist within rooms with physical barriers - walls and one or possibly two access doors. As such, nonauthorised access can be controlled easily. However, most Class IV lasers have a remote inter-lock jack socket, whereby door locks and warning lights can be activated during laser emission. Those dental clinics that operate a multi-chair, open-plan environment would need to address the requirement in greater detail. During laser treatment, only the clinician, assistant and patient should be allowed within the controlled area.

\section{Laser safety features}

All lasers have in-built safety features that must be cross-matched to allow laser emission (Figs 6-14). These include:

- Emergency 'Stop' button

- Emission port shutters to prevent laser emission until the correct delivery system is attached

- Covered foot-switch, to prevent accidental operation

- Control panel to ensure correct emission parameters

- Audible or visual signs of laser emission

- Locked unit panels to prevent unauthorised access to internal machinery

- Key or password protection

- Remote inter-locks.

\section{Eye protection}

All persons within the controlled area must wear appropriate eye protection during laser 
Fig. 16 CE mark and OD values for wavelength protection $(>5.0)$

Fig. 17 Test firing procedures for $\mathrm{CO}_{2}$ (a), diode (b) and Er:YAG (c) lasers. Low-power settings and suitable attenuation materials (water and dark paper) allow pre-treatment checks as to correct laser function and patency of delivery systems

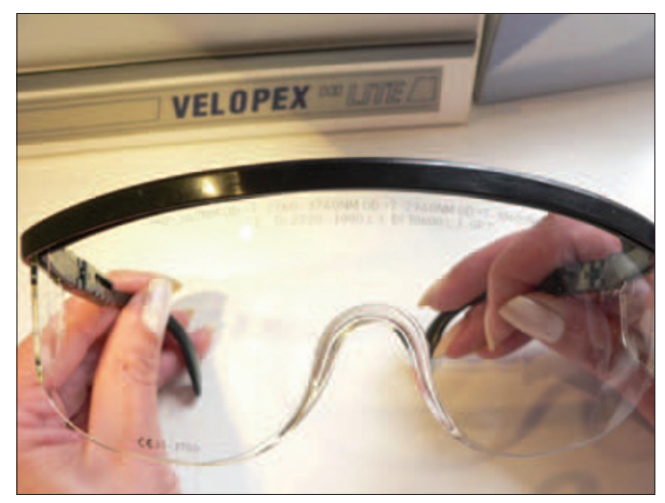

a strictly-enforced written policy. In Europe, laser eye protection must conform to either EN 207 or EN 208, and be CE marked to indicate compliance with European legislation. All protection glasses or goggles should be marked with the wavelength for which protection is given, together with a value of optical density (OD). ${ }^{41}$ The OD refers to the ability of a material to reduce laser energy of a specific wavelength to a safe level below the MPE. The OD value should be '5.0' or above for adequate protection. In addition, through the new regulation, other factors are now deemed necessary and these are listed as follows:

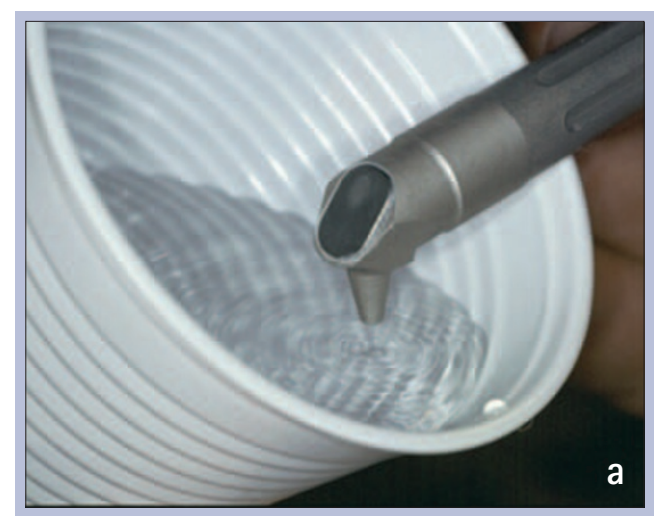

- Requirements under ANSI Z 136 (USA): OD values $>5$ to ensure attenuation to MPE values

- Requirements under EN207/208/60825: direct impact (DIN) values $>5$. Under this directive, protective eyewear should be able to attenuate direct beam exposure to MPE values within the following parameters: 10 seconds (continuous wave (CW) emission) and 100 pulses (free-running pulsed emission)

- Requirements under ANSI \&t EN 207: protective laser eyewear should carry specific labelling to define: OD, optical density; DIR operation mode; wavelength (nm); L6A protective grade; $\mathrm{RH}$ manufacturer's mark; DIN testing standard; CE (applicable for European distribution).

The L6A protective grade defines the suitability for the eyewear within clinical, industrial or research conditions. OD and DIN values should be $>5.0$. Wavelength values may be specific, eg $400 \mathrm{~nm}$, or grouped, eg 2,780$10,600 \mathrm{~nm}$. 'DIR' defines the operation (emission) mode of the laser. Each value is measured against the following coding: ' $\mathrm{D}$ ' = CW mode, 'I' = pulsed mode, 'R' = Q-switched mode.

An example of what should appear on a pair of correctly prescribed Nd:YAG protective glasses is as follows: 0D5/ IR 1064nm/ L6A/ $\mathrm{RH} / \mathrm{DIN} 5$ (+CE).

\section{Test firing}

Prior to any laser procedure and before admitting the patient, either the clinician or LSO should test-fire the laser. This is to establish that the laser has been assembled correctly, is working correctly and that laser emission is occurring through the delivery system. Protective eyewear is worn and all other safety measures met. The laser is directed towards a suitable absorbent material, eg water for long wavelengths and dark coloured paper for short wavelengths, and operated at the lowest power setting for the laser being used (Fig. 17). Following this, the laser is inactivated and the patient admitted.

wavelength being used, these should free of any scratches or damage and be constructed with side protection (Figs 15 and 16).

Such eye protection must then be properly specified for the exposure conditions that could occur, and its use must be subject to

\section{Local rules}

As with ionising radiation, a set of local rules must be compiled for practices carrying out 
laser treatment. The LPA can help with drawing up this document, but it should include the following:

- Name and address of the practice

- Each laser used, identified by manufacturer, wavelength, emission mode, power output, delivery system and serial number

- Personnel permitted to use the laser

- Designation of the authority and responsibility for the evaluation and control of laser hazards to a laser safety officer

- A written laser safety policy, to include all safety aspects of laser use

- Establishment of a quality assurance program including regular inspection and maintenance of the laser equipment

- Training and education of personnel involved in the use of lasers

- Management of incidents and accidents, including reporting, investigation, analysis and remedial action.

The local rules should be read and signed by all practice personnel involved in delivery of laser treatment and should be updated regularly.

\section{Training}

All staff members should receive objective and recognised training in the safety aspects of laser use within dentistry, as with other specialties. ${ }^{42-44}$ There is no legal obligation for this, although the Healthcare Commission would consider this to be part of the national minimal standards, against which the registered practice is inspected. National bodies, such as the National Physics Laboratory and the NRPB, offer courses in laser safety, although dental laser organisations such as ESOLA and the ALD carry examination-based LSO grading courses.

\section{CONCLUSION}

The consequence of excess laser power delivered to target tissue has been presented in previous articles in this series. Above a range of maximum permitted exposure values, nontarget tissue is subject to accidental exposure which, in the case of the eye, can result in permanent damage. Anyone working with or responsible for potentially hazardous laser equipment should be properly trained in laser safety, be aware of the nature of laser hazards and understand the procedures and safeguards that need to be implemented. Employers have to establish an adequate safety policy for the management and control of risks arising from the use of laser equipment.

The current legal framework for laser safety is a somewhat blurred overlap of competing regulations, but a 'best practice' approach to laser safety, often to address a 'worst case' scenario, is essential. The classification of lasers defines power capability relative to ocular risk, protective eyewear is specified to attenuate laser light within dedicated individual limits and the general approach to laser safety within the workplace serves to protect the patient and staff.

1. Statutory Instrument 2004 No.664. The health and social care (community health and standards) act 2003 (commission for healthcare audit and inspection and commission for social care inspection) (transitional and consequential provisions) order 2004. London: The Stationery Office, 2004.

2. Sliney D H. Evolving issues in laser safety. J Laser App/ 1997: 9: 295-300.

3. Source: UK Health Protection Agency, 2005.

4. International Electrotechnical Commission. Safety of laser products - part 1: equipment classification, requirements, and user's guide. IEC 60825-1/A2:2001. Geneva: IEC, 1993; with amendment 2, 2001.

5. European Committee for Electrotechnical Standardization. Safety of laser products - part 1: equipment classification, requirements, and user's guide. Brussels: European Committee for Electrotechnical Standardization, 1994; with amendment 2, 2001.

6. Health and social care (community health and standards) act 2003. Chapter 43 explanatory notes. London: The Stationery Office, 2003.

7. Safety of laser products - part 14: a user's guide. PD IEC TR 60825-14:2004. British Standards, 2004.

8. Takac S, Stojanovic S. Classification of laser irradiation and safety measures. Med Preg/ 1998; 51: 415-418.

9. Sliney D, Aron-Rosa D, DeLori F et al. Adjustment of guidelines for exposure of the eye to optical radiation from ocular instruments: statement from a task group of the International Commission on Non-lonizing Radiation Protection (ICNIRP). Appl Opt 2005; 44: 2162-2176.

10. International Electrotechnical Commission. Safety of laser products - part 9: compilation of maximum permissible exposure to incoherent radiation. IEC TR 60825-9: 1999-10. Geneva: IEC, 1999.

11. Sethi C S, Grey R H, Hart C D. Laser pointers revisited: a survey of 14 patients attending casualty at the Bristol Eye Hospital. Br J Ophthalmol 1999; 83: 1164-1167.

12. Robertson D M, McLaren J W, Salomao D R, Link T P. Retinopathy from a green laser pointer: a clinicopathologic study. Arch Ophthalmol 2005; 123: 629-633.

13. Reidenbach H D, Dollinger K, Hofmann J. Field trials with low power lasers concerning the blink reflex. Biomed Tech (Berl) 2002; 47 (Suppl 1): 600-601.

14. Chandra $P, A z a d R$ V. Laser rangefinder induced retinal injuries. Indian J Ophthalmol 2004; 52: 349.

15. Schuele G, Rumohr M, Huettmann G, Brinkmann R. RPE damage thresholds and mechanisms for laser exposure in the microsecond-to-millisecond time regimen. Invest Ophthalmol Vis Sci 2005; 46: 714-719.

16. Moseley H. Operator error is the key factor contributing to medical laser accidents. Lasers Med Sci 2004; 19: 105-111.

17. Barkana Y, Belkin M. Laser eye injuries. Surv Ophthalmol 2000; 44: 459-478

18. Thach A B. Laser injuries of the eye. Int Ophthalmol Clin 1999; 39(2): 13-27.

19. Hagemann L F, Costa R A, Ferreira H M, Farah M E. Optical coherence tomography of a traumatic neodymium:YAG laser-induced macular hole. Ophthalmic Surg Lasers Imaging 2003; 34: 57-59.

20. Chuang L H, Lai C C, Yang K J, Chen T L, Ku W C. A traumatic macular hole secondary to a high-energy Nd:YAG laser. Ophthalmic Surg Lasers 2001; 32: 73-76.

21. Clarke T F, Johnson T E, Burton M B, Ketzenberger B, Roach W P. Corneal injury threshold in rabbits for the $1540 \mathrm{~nm}$ infrared laser. Aviat Space Environ Med 2002; 73: 787-790.

22. Harris M D, Lincoln A E, Amoroso P J, Stuck B, Sliney D. Laser eye injuries in military occupations. Aviat Space Environ Med 2003; 74: 947-952.

23. Widder R A, Severin M, Kirchhof B, Krieglstein G K. Corneal injury after carbon dioxide laser skin resurfacing. Am J Ophthalmol 1998; 125: 392-394.

24. Miedziak A I, Gottsch J D, Iliff N T. Exposure keratopathy after cosmetic $\mathrm{CO}_{2}$ laser skin resurfacing. Cornea 2000; 19: 846-848.

25. Grossman A R, Majidian A M, Grossman P H. Thermal injuries as a result of $\mathrm{CO}_{2}$ laser resurfacing. Plast Reconstr Surg 1998; 102: 1247-1252. 
26. Ilgner J, Falter F, Westhofen M. Long-term follow-up after laser-induced endotracheal fire. J Laryngol Otol 2002; 116: 213-215.

27. Macdonald A G. A brief historical review of non-anaesthetic causes of fires and explosions in the operating room. Br J Anaesth 1994; 73: 847-856.

28. Sosis M B, Braverman B. Evaluation of foil coverings for protecting plastic endotracheal tubes from the potassium-titanyl-phosphate laser. Anesth Analg 1993; 77: 589-591.

29. Cork R C. Anesthesia for otolaryngologic surgery involving use of a laser. Contemp Anesth Pract 1987; 9: 127-140.

30. Dave R, Mahaffey P J. The control of fire hazard during cutaneous laser therapy. Lasers Med Sci 2002; 17: 6-8.

31. Scott E, Beswick A, Wakefield K. The hazards of diathermy plume. Part 2. Producing quantified data. Br J Perioper Nurs 2004; 14: 452, 454-456

32. Garden J M, O'Banion M K, Bakus A D, Olson C. Viral disease transmitted by laser-generated plume (aerosol). Arch Dermatol 2002; 138: 1303-1307.

33. Kunachak S, Sobhon P. The potential alveolar hazard of carbon dioxide laser-induced smoke. J Med Assoc Thai 1998; 81: 278-282.

34. McKinley I B Jr, Ludlow M O. Hazards of laser smoke during endodontic therapy. J Endod 1994; 20: 558-559.
35. Sterenborg H J. Lasers in dentistry. 9. Safety in laser use. Ned Tijdschr Tandheelkd 2003; 110: 62-66.

36. Andersen K. Safe use of lasers in the operating room - what perioperative nurses should know. AORN J 2004; 79: $171-88$.

37. Marshall W J, Aldrich R C, Zimmerman S A. Laser hazard evaluation method for middle infrared laser systems. J Laser App/ 1996; 8: 211-216.

38. Schmidt F U. Ophthalmological risks and hazards of laser use in the head and neck region. Adv Otorhinolaryngol 1995; 49: 23-26

39. Szymanska J. Work-related vision hazards in the dental office. Ann Agric Environ Med 2000; 7: 1-4.

40. Bhattacharyya N, Richard C. A comparison of ocular protective measures during carbon dioxide laser laryngoscopy. Arch Otolaryngol Head Neck Surg 2004; 130: 1289-1292.

41. Laser safety eyewear. Health Devices 1993; 22: 159-204.

42. Youker S R, Ammirati C T. Practical aspects of laser safety. Facial Plast Surg 2001; 17: 155-163.

43. Lewandowski M A, Hinz M W. A simple approach to industrial laser safety. Health Phys 2005; 88 (Suppl 2): S24-S30.

44. Edwards B E, Barnes L K, Gibbs J B, Nguyen G B. Medical laser safety hazard evaluation. Health Phys 2002; 83 (Suppl 8): S36-S44. 